e-Mosaicos - Revista Multidisciplinar de Ensino, Pesquisa, Extensão e Cultura do Instituto de Aplicação Fernando Rodrigues da Silveira (CAp-UERJ) ANO 1 - V. 1 - N. 1 - JUNHO 2012 - ISSN: 2316-9303

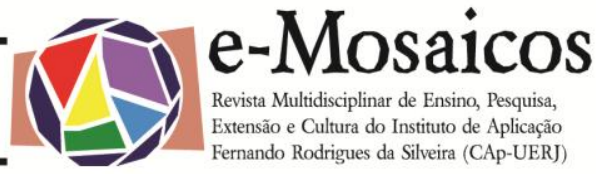

\title{
Escola, culturas e diferenças: experiências e desafios na educação básica
}

\author{
Roberta Sales Lacê Rosário ${ }^{1}$
}

FEBF/UERJ

O livro reúne artigos de vários professores-pesquisadores atuantes nos anos iniciais da educação básica, que propõem um estimulante e compromissado debate diante das questões que envolvem as relações étnico-raciais presentes nas práticas pedagógicas. Dessa forma, a obra está organizada em um conjunto de textos produzidos a partir de reflexões sobre a prática cotidiana, tendo como principal ponto de reflexão a alteração da LDB - Lei de Diretrizes e Bases para a Educação Nacional, pela Lei $10639 / 2003$, atual Lei $11465 / 2008$ - que, além de outros objetivos, propõem a reeducação das relações étnico-raciais através da valorização da História e da cultura dos africanos e dos afro-brasileiros no currículo da educação básica.

Dentre as inúmeras questões suscitadas aos leitores, está posto, enquanto desafio urgente, o reconhecimento da diferença e, por conseguinte, a promoção da equidade nas práticas cotidianas da escola. Podemos, então, perceber a preocupação e sinalização dos autores, em seus artigos, da necessidade de discutirmos uma reconfiguração dos processos de ensino-aprendizagem nos anos iniciais de formação das crianças e na educação básica. Nesse sentido, os textos apresentam demandas que surgem no desenrolar das práticas de professores e professoras, ao privilegiarem o fortalecimento do direito à diferença, no que diz respeito ao processo de produção e construção do conhecimento pelos diferentes sujeitos.

Ao nos voltarmos para o debate das re- lações étnico-raciais como ponto de interseção nas propostas de aprofundamento dos estudos sobre a diferença nas relações culturais, compreendemos a proposição dos autores, de diferentes maneiras em seus artigos, apontando para uma produção de identidade, que há muitos anos se constituiu, imbuída por uma visão e formação etnocêntrica. Desta forma, tal percepção erigiuse e construiu um cenário de produção e desenvolvimento de práticas de discriminação e de desigualdade entre os sujeitos. Onde, ao menor ato de manifestação de desvalorização e subalternização dos negros e afrodescendentes, se dava a legitimar por concepções hierarquizadas do saber-poder.

Os artigos se dispõem, na organização do livro, subdividos em seções temáticas de articulação, são elas: "Escola e relações raciais nos anos iniciais"; "Escola e identidades culturais na educação básica" e "Crianças e histórias afrodescendentes na educação básica". Ao longo destas seções, poderemos encontrar os artigos produzidos pelos professores e pelas professoras, em sua grande maioria, atuantes no Departamento do Ensino Fundamental do Instituto de Aplicação Fernandes Rodrigues da Silveira - CAp-UERJ.

Na primeira seção do livro - "Escola e relações raciais nos anos iniciais" podemos observar os artigos das professoras que problematizam as relações raciais nos anos iniciais do Ensino Fundamental. Iniciaremos pelo artigo da professora Maria Cláudia de Oliveira Reis, "Por que estudar 
e-Mosaicos - Revista Multidisciplinar de Ensino, Pesquisa, Extensão e Cultura do Instituto de Aplicação Fernando Rodrigues da Silveira (CAp-UERJ) ANO 1 - V. 1 - N. 1 - JUNHO 2012 - ISSN: 2316-9303

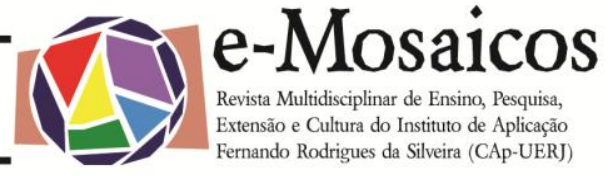

a História da África na Escola?", onde a autora traz relatos de sua experiência e destaca, em seu artigo, a importância de conhecermos nossa própria História. Para tanto, nesse movimento de busca pelo entendimento de nossa História, é imprescindível que reconheçamos que "o continente africano constitui uma parte significativa de nossas origens". Em seus relatos, a autora aponta para uma visão marcadamente estereotipada e preconceituosa de seus estudantes do $5^{\circ}$ ano de escolaridade que, através de suas falas e escritos, sinalizam a urgência em se desconstruir (ou, da desconstrução de) visões e posturas que ainda habitam o imaginário social, influenciadas por perspectivas etnocêntricas.

No segundo artigo desta seção: "Cenas da diferença na escola: a feía cor do preconceito", a professora Mônica Andréa Oliveira Almeida apresenta duas cenas ocorridas em duas turmas distintas do $3^{\circ}$ ano de escolaridade. A autora aponta as cenas como ponto de discussão em torno das relações étnico-raciais que nos exigem um olhar atento para os conflitos gerados por diferentes situações. Tais conflitos são permeados por atitudes que denunciam recusas, desvalorização dos diferentes modos de perceber a si próprio e ao outro como pertencentes às raízes afrodescendentes. A autora salienta que é preciso perceber a escola como "espaço de diálogo entre diferentes manifestações culturais onde a diversidade presente neste ambiente possa proporcionar o desenvolvimento de sujeitos...". Com isso, afirma que as experiências vividas no cotidiano da sala de aula, os embates e enfrentamentos, são necessários para a promoção de uma prática pedagógica que privilegie as diferenças e, gradativamente, combata a "feia cor do preconceito".

No terceiro artigo: "Mas, ele não nas- ceu assim... ficou escurinho": 0 papel da escola diante do "diferente, a autora Luana Carvalho de Melo nos traz reflexões a partir do desenvolvimento do projeto "África, Berço do Conhecimento", com seus alunos. A autora evidencia, em diferentes atividades em sala de aula, através das falas de seus alunos, uma prática de negação do "outro", enquanto o "outro diferente", ou por ser negro, ou gordo, ou mesmo por não atender aos padrões estéticos de beleza europeia, como por exemplo: cabelo liso, pele clara. Nesses diálogos e enfrentamentos, a autora se interroga como abordar o conflito entre os "diferentes", assim como "se rebelar contra a intolerância, a ideia do negro apenas como escravo".

A autora Jaqueline de Fátima dos Santos Morais nos convida a "reacender $e$ alimentar nossas ações e utopias na construção de novas formas de sociabilidade mais fraternas e emancipatórias", no quarto artigo desta seção: "Negritude, narrativas e atravessamentos no cotidiano do Ensino Fundamental". Neste sentido, revela um pouco de suas inquietudes e desafios proporcionados pelos acontecimentos vivenciados no cotidiano da sala de aula. No encontro com a diferença, enquanto professora-pesquisadora da própria prática em classes de alfabetização, agora o $1^{\circ}$ ano de escolaridade, na busca pelo diálogo pelo entendimento de questões relacionadas aos saberes e práticas subalternizadas excludentes, observa um tempo que pressupõe avanços e retornos à tradição, simultaneamente.

No quinto artigo da seção, os autores Cristina Maria Clemente Ribeiro e Luiz Fernandes de Oliveira, nos trazem um questionamento - "Uma outra lógica é possível? Linguagem matemática e culturas africanas nos anos iniciais". Neste 
e-Mosaicos - Revista Multidisciplinar de Ensino, Pesquisa, Extensão e Cultura do Instituto de Aplicação Fernando Rodrigues da Silveira (CAp-UERJ) ANO 1 - V. 1 - N. 1 - JUNHO 2012 - ISSN: 2316-9303

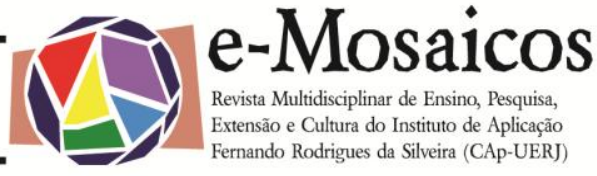

sentido, ao discutirem a linguagem enquanto construção social do sujeito, os autores trazem a produção matemática dos povos africanos, invisibilizada pela visão eurocêntrica de ciência. Assim como o artigo anterior, os autores discutem a subalternização de saberes e conhecimentos, aqui com ênfase nos povos não ocidentais. Buscam, através do resgate da História, o entendimento das abordagens no ensino da Matemática através do surgimento das primeiras bases tecnológicas e científicas no continente africano e, desta forma, apontam para "uma outra História a ser contada".

A segunda seção do livro - "Escola e identidades culturais na educação básica" - traz uma reunião de artigos que discutem questões de identidades culturais e suas implicações no contexto da escola. No primeiro artigo, "Aqui nessa escola não se faz oração, não professora?" A perspectiva cultural da religião e da diferença no currículo, as autoras Cristiane Gomes de Oliveira e Rita de Cássia Prazeres Frangella trazem tensões acerca da produção curricular que se apresenta como produção cultural dos diferentes sujeitos, negociada no cotidiano da sala de aula. Para tanto, o artigo parte do desenvolvimento de projetos que buscam oportunizar às crianças "um espaço de encontro/desafio com a diferença, em processos que impliquem a significação não como homogeneização", mas em que seja possível o diálogo entre as diferentes formas de produção cultural.

$\mathrm{O}$ artigo intitulado "Minha professora pede para eu ensinar jongo para ela. Processos identitários e a mediação cultural", produzido pelos autores: Claudia Cristina dos Santos Andrade, Marcus Vinicius Bezerra Carvalho e Renato de Alcântara, traz três cenas que apresentam elementos em comum, a partir da dança do jongo em diferentes contextos - entre a tradição e $a$ reinvenção. A escolha de dar início ao artigo pelas cenas, como apontam os autores, "é uma forma de partilhar a vivência, aproximando-nos, assim, dos sentidos por ela emanados", o que, de certa forma, contribui para o reconhecimento e reforço dos laços e narrativas que carregam marcas identitárias. No contínuo movimento de identificação e mediação discutido pelos autores, é possível percebermos a evidência de uma prática cultural que se re-afirma e se revela através dos múltiplos processos que envolvem a manifestação cultural.

As autoras Cláudia Hernandez Barreiros e Jonê Carla Baião, no artigo: "Preto pra não dizer negro, que é esquisito". Polifonia racista e construção de identidades de adolescentes pobres do Rio de Janeiro - nos possibilitam refletir, a partir do desdobramento de duas cenas vivenciadas com uma turma do $6^{\circ}$ ano de escolaridade. No texto, as autoras problematizam questões relacionadas aos diferentes modos de ser e se reconhecer negro e o que isso implica na relação com o outro, através dos relatos e registros dos alunos. $\mathrm{O}$ que, de fato, nos possibilita perceber como são constituídas as relações entre os pares desta turma e assim, "o enfrentamento dos conflitos gerados no interior das diferenças culturais". As professoras acreditam na interlocução e na partilha de suas investigações, como possibilidade de retomar o diálogo e, em grupo, "constituir saberes didáticos para lidar com a diferença na escola".

No artigo "Palavras são pedaços de vida! Quais palavras temos permitido entrar na escola?", a autora Margarida dos Santos nos interroga: "ao reconhecermos os usos da escrita e da leitura de nossos alunos, conseguimos valorizá-los?". Neste sentido, a autora nos convida a refletir 
e-Mosaicos - Revista Multidisciplinar de Ensino, Pesquisa, Extensão e Cultura do Instituto de Aplicação Fernando Rodrigues da Silveira (CAp-UERJ) ANO 1 - V. 1 - N. 1 - JUNHO 2012 - ISSN: 2316-9303

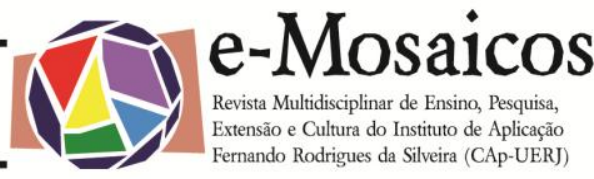

sobre as possibilidades de superação do fracasso escolar das crianças das classes populares que, em seus escritos e falas, são silenciados e marcados pela escola. Ela traz, no artigo, os escritos de seus alunos como forma de anunciar produções culturais e sociais de leitura e escrita que precisam ser reconhecidas e valorizadas no âmbito da escola. Desta forma, a autora problematiza a questão dos saberes legitimados e autorizados a entrar na escola e, assim, ressalta a necessidade de estimular uma produção que privilegie as diferentes formas de expressar o conhecimento, ao invés de reproduzir escritos que não fazem sentido.

As autoras Adriana da Silva Tomaz, Claudia Cristina dos Santos Andrade, Cristina Maria Clemente Ribeiro, Marliza Bode de Moraes e Mônica Regina Ferreira Lins produziram juntas o artigo: "Reflexões sobre práticas avaliativas e o jubilamento no Colégio de Aplicação da UERJ". No texto, as autoras refletem sobre o processo de avaliação e, assim, trazem, ao diálogo para a análise, suas práticas cotidianas e as narrativas dos alunos quando indagados sobre a avaliação e a jubilação no Instituto de Aplicação Fernando Rodrigues da Silveira. Para tanto, o texto traz a proposição dos autores em discutir a partir de suas práticas pedagógicas, refletidas por uma proposta de avaliação inclusiva, porém vislumbrando o desafio de pensar os sentidos de tais práticas de avaliação e jubilação enquanto possíveis mecanismos de controle e classificação. $\mathrm{Na}$ tentativa de problematizar os sentidos dados aos processos avaliativos, os professores, ao evidenciarem as narrativas dos alunos, permitem trazer ao centro do debate, "os silêncios, os medos, as (in)certezas e as diferenças" que permeiam o fazer cotidiano dos alunos e professores do Colégio de Aplicação da UERJ.
Na terceira seção do livro - Crianças e histórias afrodescendentes na educação básica - podemos observar, no primeiro artigo, da autora Mônica Regina Ferreira Lins, um apelo ao resgate, ao enfoque dos "personagens que durante muito tempo foram invisibilizados nos livros escolares de História". Em "Rio, civiliza-te! E samba. Pelas ruas, nos cortiços, nas revoltas, nas outras histórias, uma cidade viva na memória", a autora nos leva a um passeio ao passado, uma oportunidade de revisitar a memória da cidade do Rio de Janeiro, enquanto expressão de momentos e movimentos de ritos e resistência. Neste sentido, a autora nos convida a refletir sobre a escrita da História do Brasil, a partir da sistematização e generalização de povos subjugados e, assim, a problematização das relações de inferioridade de um povo em detrimento do outro.

No artigo "África e Lei 10639/03. Da militância negra aos espaços escolares", o autor Luiz Fernandes de Oliveira aborda a questão do mito da "democracia racial", assim como o enaltecimento da miscigenação, como insuficientes para silenciar o "protesto negro". Desta forma, o artigo destaca diferentes movimentos, especificamente os movimentos negros, como pontos de articulação e transformação de períodos que marcaram a História do Brasil. Neste sentido, busca a desconstrução da ideia de uma comunidade negra pós-abolição, analfabeta e desorganizada, ao apresentar, nas diferentes épocas, a luta e militância de movimentos que, apesar das opressões e marginalização, proporcionaram mudanças importantes no cenário educacional do país. Certamente, tais movimentos foram fundamentais para que, atualmente, após anos de lutas e resistência, possamos refletir a partir de trajetórias de discriminação, porém de ressignificação, e, assim, colocarmos "a 
e-Mosaicos - Revista Multidisciplinar de Ensino, Pesquisa, Extensão e Cultura do Instituto de Aplicação Fernando Rodrigues da Silveira (CAp-UERJ)

ANO 1 - V. 1 - N. 1 - JUNHO 2012 - ISSN: 2316-9303

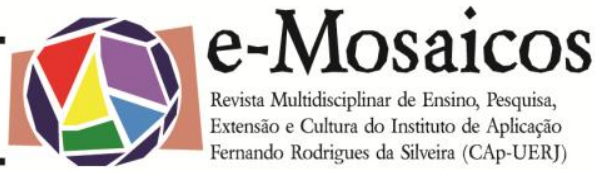

questão racial no cotidiano de discussões acadêmicas e de políticas públicas".

1 robertarose1@yahoo.com.br - Mestranda do Programa de Pós-Graduação Educação, Cultura e Comunicação nas Periferias Urbanas FEBF/UERJ. Participa do Grupo de Estudo Currículo, Formação e Educação em Direitos Humanos - GECEDH, atuando como pesquisadora da sala de aula Revoluti do Instituto de Aplicação Fernando Rodrigues da Silveira - CAp/UERJ. 